\title{
Analisis Materi Struktur Atom Pada Buku Teks Kimia Kelas X SMA/MA
}

\author{
Syahra Ayu Pratiwi*, Abdul Hadjranul Fatah, Syarpin \\ Program Studi Pendidikan Kimia, Jurusan MIPA, FKIP, Universitas Palangka \\ Raya, Indonesia \\ Email: Syahraayupratiwii@gmail.com
}

Diterima: 05 Maret 2020; Disetujui: 20 Maret 2020; Diterbitkan: 29 Maret 2020

\begin{abstract}
ABSTRAK
Penelitian ini merupakan penelitian Kualitatif. Metode penelitian ini adalah metode penelitian deksriptif. Instrumen penelitian yang digunakan adalah tabel identifikasi label konsep dan jenis representasi, tabel identifikasi kesesuaian label konsep dengan silabus, model struktur makro wacana, dan tabel kriteria representasi kimia. Hasil penelitian menunjukkan bahwa label konsep yang terdapat pada buku A sebanyak 27 label konsep dan memiliki 50 jenis representasi yang terbagi dalam tipologi makroskopik, submikroskopik, simbolik. Label konsep yang terdapat pada buku B sebanyak 32 label konsep dengan 68 jenis representasi yang terbagi dalam tipologi makroskopik, submikroskopik, dan simbolik. Kesesuaian label konsep buku teks A dan buku teks B terhadap silabus kimia kuriukulum 2013 terdapat 31 label konsep yang sesuai dengan silabus kimia K-13. Struktur makro buku A mencapai level 7 dimensi elaborasi, dan buku B mencapai level 7 dimensi elaborasi. Kriteria representasi kimia konsep struktur atom pada buku A terdapat 21 representasi, dan pada buku B terdapat 26 representasi.
\end{abstract}

Kata Kunci: analisis, buku teks, materi, struktur atom

\section{PENDAHULUAN}

Ilmu kimia merupakan salah satu cabang ilmu pengetahuan alam yang bersifat abstrak dan mencakup konsep, aturan, hukum, prinsip, dan teori. Perubahan dan konsep-konsep dalam ilmu kimia sebagian besar merupakan fenomena yang tidak dapat diamati secara langsung oleh indra penglihatan manusia (Kean \& Middlecamp, 1985). Ilmu kimia yang bersifat abstrak inilah yang menyebabkan banyak peserta didik seringkali mengalami kesulitan dalam memahami ilmu kimia dengan benar. Salah satunya yaitu pada konsep struktur atom. Konsep-konsep dalam ilmu kimia khususnya pada konsep struktur atom merupakan suatu hal yang berkelanjutan dan berkaitan satu sama lain. Pemilihan dan penggunaan bahan ajar yang tepat mampu membuat peserta didik lebih mudah dalam mempelajari dan memahami mata pelajaran kimia yang bersifat abstrak dengan lebih mudah. Mengingat bahwa buku teks merupakan salah satu bahan ajar penting yang digunakan sebagai sumber informasi utama disekolah, maka perlu pemilihan buku teks yang tepat demi mencapai tujuan pembelajaran. Salah satu cara untuk mengetahui ketepatan pemilihan buku pelajaran, dapat dengan cara menganalisis buku tersebut. Melalui analisis buku teks, maka dapat diketahui bagaimana buku tersebut menjelaskan dan menggambarkan konsepkonsep kimia yang bersifat abstrak, dan juga dapat diketahui kekurangan dan 
kelebihan buku teks. Gkitzia (2011) menyatakan bahwa para ahli telah menemukan sistem khusus simbol (molekul, model molekul, rumus, persamaan kimia, proyeksi Ficher, dll), yang mampu membantu untuk berkomunikasi dan memvisualisasikan kimia. Visualisasi kimia melalui sistem khusus simbolis dapat disebut sebagai "representasi kimia" atau "representasi". Berkaitan dengan pernyataan Huddle et al, . (2000) bahwa kesulitan siswa dalam memahami konsepkonsep kimia disebabkan oleh buku teks yang digunakan tidak mengaitkan tiga level representasi kimia. Tiga level representasi kimia tersebut antara lain makroskopik, submikroskopik, dan simbolik. Gkitzia (2011) menyatakan bahwa representasi kimia memiliki beberapa kriteria representasi. Kriteria representasi kimia tersebut antara lain: Jenis representasi yang disimbolkan R1; Fitur interpretasi yang disimbolkan R2; Keterkaitan dengan teks yang disimbolkan R3; Ada atau tidaknya keterangan gambar yang disimbolkan R4; Derajat keterhubungan antara komponen multiple representasi yang disimbolkan R5.

Konsep merupakan istilah yang digunakan untuk menggambarkan secara abstrak suatu objek. Melalui konsep diharapkan dapat menyederhanakan pemikiran dengan menggunakan suatu istilah. Konsep mempunya arti yang tidak sederhana. Namun, pada hakekatnya konsep itu berfungsi untuk mewujudkan suatu yang abstrak menjadi konkrit. Herron (1977) mengidentifikasi karakteristik yang dimiliki konsep meliputi: label konsep, atribut konsep (atribut kritis dan atribut variabel) dan jenis konsep.

Buku teks adalah buku pelajaran dalam bidang studi tertentu yang dijadikan buku standar, yang disusun oleh para pakar dalam bidang itu untuk maksudmaksud dan tujuan instruksional, yang lengkapi dengan sarana-sarana pengajaran yang serasi dan mudah dipahami oleh para pemakainya di sekolah-sekolah dan perguruan tinggi sehingga dapat menunjang sesuatu program pengajaran (Tarigan, 1986).

Buku teks yang baik adalah buku teks yang mampu menjadi sumber pengetahuan yang tersusun secara sistematiis dan memungkinkan pembaca untuk menemukan informasi yang dibutuhkan dengan cepat. Semakin baik buku teks, maka semakin sempurna pengajaran mata pelajaran yang ditunjangnya (Tarigan, 2009).

Silabus mata pelajaran kimia merupakan rencana pembelajaran pada mata pelajaran kimia yang mencakup kompetensi inti, kompetensi dasar, materi pokok, kegiatan pembelajaran, penilaian, alokasi waktu, dan sumber/bahan/alat belajar. Silabus juga dapat dikatakan sebagai seperangkat dan pengaturan tentang kegiatan pembelajaran, pengelolaan kelas, pemilihan buku pelajaran, penulisan buku, dan penilaian hasil belajar.

Struktur makro wacana merupakan tahap dimana satu ide berhubungan dengan ide selanjutnya. Hal ini dilakukan untuk mengetahui keluasan dan kedalaman materi atau konsep dibahas. Keluasan materi dapat diketahui melalui dimensi progresi, dan kedalaman materi dapat diketahui melalui dimensi elaborasi. Struktur makro wacana ini merupakan makna global atau umum suatu teks yang dapat dipahami dengan melihat topik dari suatu teks tersebut.

Representasi adalah penggambaran secara fisik suatu fenomena dan/atau suatu objek yang bersifat abstrak, misalnya isyarat, gambar pada buku teks, dan 
diagram yang dihasilkan oleh siswa. Tiga representasi kimia yaitu makroskopik, submikroskopik, dan simbolik.

Gkitzia, et al., (2011) membahas mengenai lima kriteria yang dapat digunakan untuk menganalisis representasi kimia pada buku teks. Kelima kriteria ini didapatkan setelah para penyusun melakukan penelitian terhadap lima jenis buku teks di Yunani. Kriteria representasi kimia tersebut antara lain: Jenis representasi yang disimbolkan R1; Fitur interpretasi yang disimbolkan R2; Keterkaitan dengan teks yang disimbolkan R3; Ada atau tidaknya keterangan gambar yang disimbolkan R4; Derajat keterhubungan antara komponen multiple representasi yang disimbolkan R5.

Penelitian ini bertujuan untuk melakukan analisis materi ajar pada buku teks kimia SMA/MA. Penelitian serupa telah dilakukan oleh Wulandari (2019).

\section{METODOLOGI PENELITIAN}

Penelitian ini merupakan penelitian Kualitatif. Metode penelitian ini adalah metode penelitian deksriptif. Buku yang digunakan yaitu buku teks Kimia SMA/MA Kelas X Karangan Unggul Sudarmo sebagai buku A, dan buku Kimia 1 SMA/MA Kelas X karangan Abdul Haris Watoni, dkk sebagai buku C. Instrumen penelitian yang digunakan Tabel beikut:

Tabel 1. Identifikasi Label Konsep Dan Jenis Representasi.

\begin{tabular}{lcccccc}
\hline \multirow{2}{*}{ Label Konsep } & \multicolumn{6}{c}{ Tipologi } \\
\cline { 2 - 7 } & \multicolumn{2}{c}{ Makroskopik } & Submikroskopik & \multicolumn{2}{c}{ Simbolik } \\
\cline { 2 - 7 } & Narasi & Gambar & Narasi & Gambar & Narasi & Gambar \\
\hline Teori atom & $\sqrt{ }$ & $\sqrt{ }$ & $\sqrt{ }$ & - & - & - \\
Demokritus & & - & $\sqrt{ }$ & - & $\sqrt{ }$ & - \\
Nomor Massa & - & & &
\end{tabular}

Tabel 2. Identifikasi Kesesuaian Label Konsep Dengan Silabus K-13

\begin{tabular}{|c|c|c|c|c|c|c|c|c|}
\hline \multirow{3}{*}{$\begin{array}{c}\text { Kode } \\
\text { Kompete } \\
\text { nsi Dasar } \\
\text { (KD) }\end{array}$} & \multirow{3}{*}{$\begin{array}{l}\text { Kode } \\
\text { Materi } \\
\text { Pokok } \\
\text { (MP) }\end{array}$} & \multirow[b]{3}{*}{$\begin{array}{c}\text { Label } \\
\text { Konsep }\end{array}$} & \multicolumn{6}{|c|}{ Kesesuaian dengan Silabus } \\
\hline & & & \multicolumn{3}{|c|}{ Buku A } & \multicolumn{3}{|c|}{ Buku B } \\
\hline & & & $\begin{array}{c}\text { Ko } \\
\text { de } \\
\text { KD }\end{array}$ & $\begin{array}{c}\text { Ko } \\
\text { de } \\
\text { MP }\end{array}$ & $\begin{array}{c}\text { Kesesu } \\
\text { aian }\end{array}$ & $\begin{array}{c}\text { Ko } \\
\text { de } \\
\text { KD }\end{array}$ & $\begin{array}{c}\text { Ko } \\
\text { de } \\
\text { MP }\end{array}$ & $\begin{array}{c}\text { Kesesu } \\
\text { aian }\end{array}$ \\
\hline 3.1 & a.Perkemb & Teori & & & & & & \\
\hline $\begin{array}{l}\text { Mengan } \\
\text { alisis } \\
\text { Perkemb }\end{array}$ & $\begin{array}{l}\text { angan } \\
\text { model } \\
\text { atom. }\end{array}$ & $\begin{array}{l}\text { Atom } \\
\text { Demokrit } \\
\text { us }\end{array}$ & 3.2 & $\mathrm{a}$ & $\sqrt{ }$ & 3.2 & $\mathrm{a}$ & $\sqrt{ }$ \\
\hline $\begin{array}{l}\text { angan } \\
\text { Model }\end{array}$ & $\begin{array}{l}\text { b. Struktur } \\
\text { atom }\end{array}$ & $\begin{array}{l}\text { Bilangan } \\
\text { Kuantum }\end{array}$ & 4.1 & $\mathrm{e}$ & $\sqrt{ }$ & 4.1 & $\mathrm{e}$ & $\sqrt{ }$ \\
\hline Atom & Bohr dan & Bilangan & & & & & & \\
\hline 3.3 & mekanika & Kuantum & 4.2 & $\mathrm{e}$ & $\sqrt{ }$ & 4.2 & $\mathrm{e}$ & $\sqrt{ }$ \\
\hline $\begin{array}{l}\text { Mengan } \\
\text { alisis }\end{array}$ & $\begin{array}{l}\text { kuantum. } \\
\text { c. Nomor }\end{array}$ & $\begin{array}{l}\text { Azimut } \\
\text { Bilangan }\end{array}$ & & & & & & \\
\hline $\begin{array}{l}\text { Struktur } \\
\text { Atom }\end{array}$ & $\begin{array}{l}\text { atom dan } \\
\text { nomor }\end{array}$ & $\begin{array}{l}\text { Kuantum } \\
\text { Magnetik }\end{array}$ & 4.2 & $\mathrm{e}$ & $\sqrt{ }$ & 4.2 & $\mathrm{e}$ & $\sqrt{ }$ \\
\hline $\begin{array}{l}\text { Berdasar } \\
\text { kan teori }\end{array}$ & $\begin{array}{l}\text { massa. } \\
\text { d. }\end{array}$ & $\begin{array}{l}\text { Hukum } \\
\text { Perbandi }\end{array}$ & - & - & - & 3.2 & $\mathrm{a}$ & $\sqrt{ }$ \\
\hline
\end{tabular}




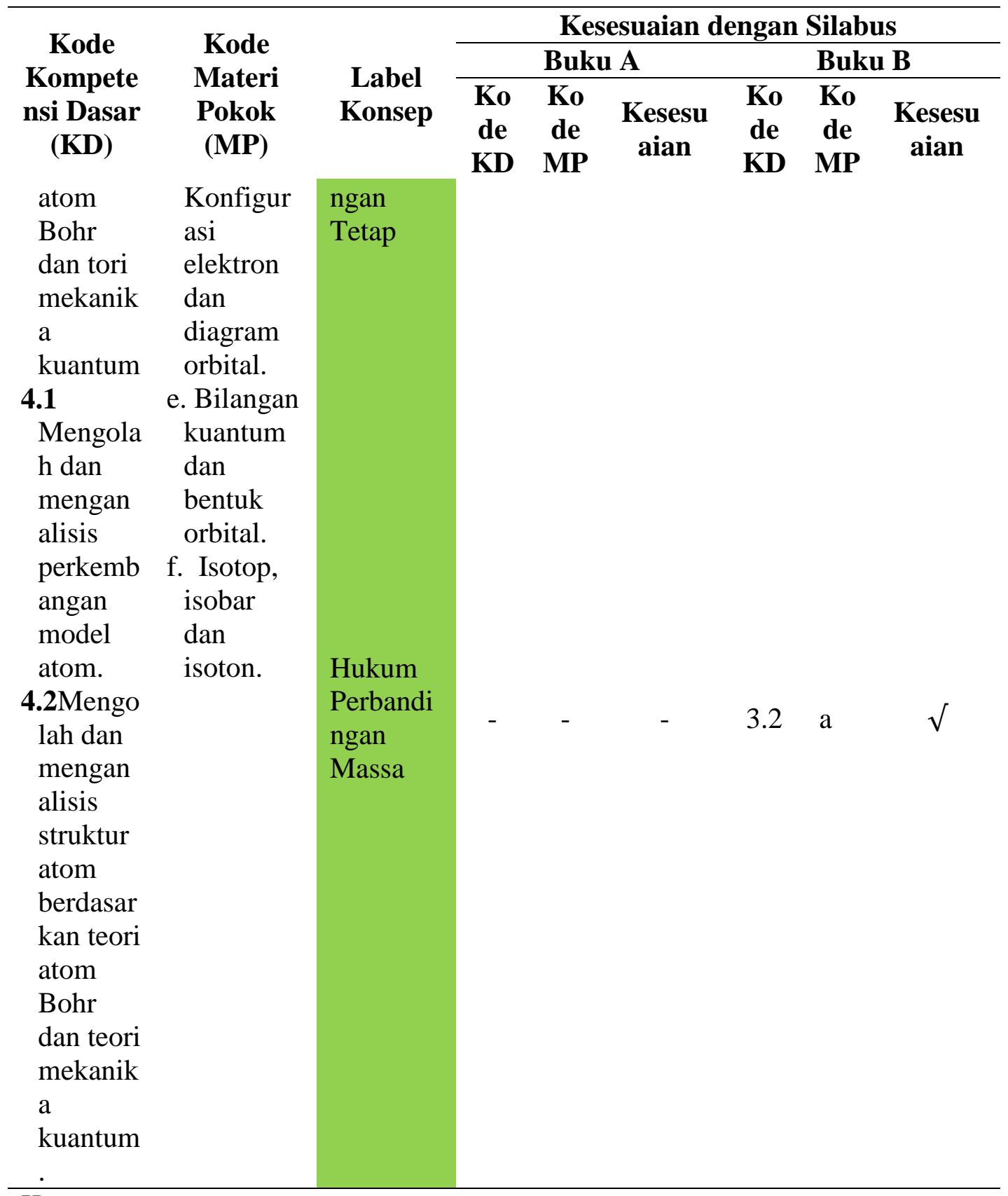

Keterangan:

: Label konsep yang sama pada buku A dan buku B

: Label konsep yang hanya dimiliki buku A.

: Label konsep yang hanya dimiliki buku B.

$\sqrt{ } \quad$ : Label konsep sesuai dengan keseluruhan KD dan MP

* $\quad$ : Label konsep kurang sesuai

- $\quad$ : Tidak ada label konsep

Tabel 3. Kriteria Representasi Kimia.

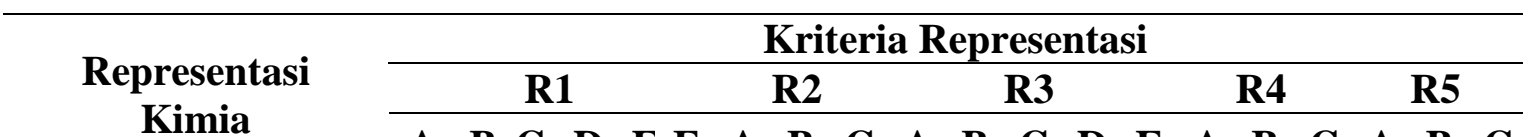

$\begin{array}{llllllllllllllllllll}\text { A } & \text { B } & C & \text { D } & \text { E } & \mathbf{F} & \text { A } & \text { B } & \text { C } & \text { A } & \text { B } & \text { C } & \text { D } & \text { E } & \text { A } & \text { B } & \text { C } & \text { A } & \text { B } & \text { C }\end{array}$ 


$\begin{array}{llllll}\begin{array}{l}\text { Gambar 1. Atom X } \\ \text { dan Y }\end{array} & \sqrt{ } & \sqrt{ } & \sqrt{ } & \sqrt{ } & \sqrt{ } \\ \begin{array}{l}\text { Gambar 2. Hukum } \\ \text { perbandingan } \\ \text { berganda }\end{array} & \sqrt{ } & \sqrt{ } & \sqrt{ } & \sqrt{ } & \sqrt{ } \\ \begin{array}{l}\text { Gambar 3. Tabung } \\ \text { sinar katode }\end{array} & \sqrt{ } & \sqrt{ } & \sqrt{ } & \sqrt{ } & \sqrt{ }\end{array}$

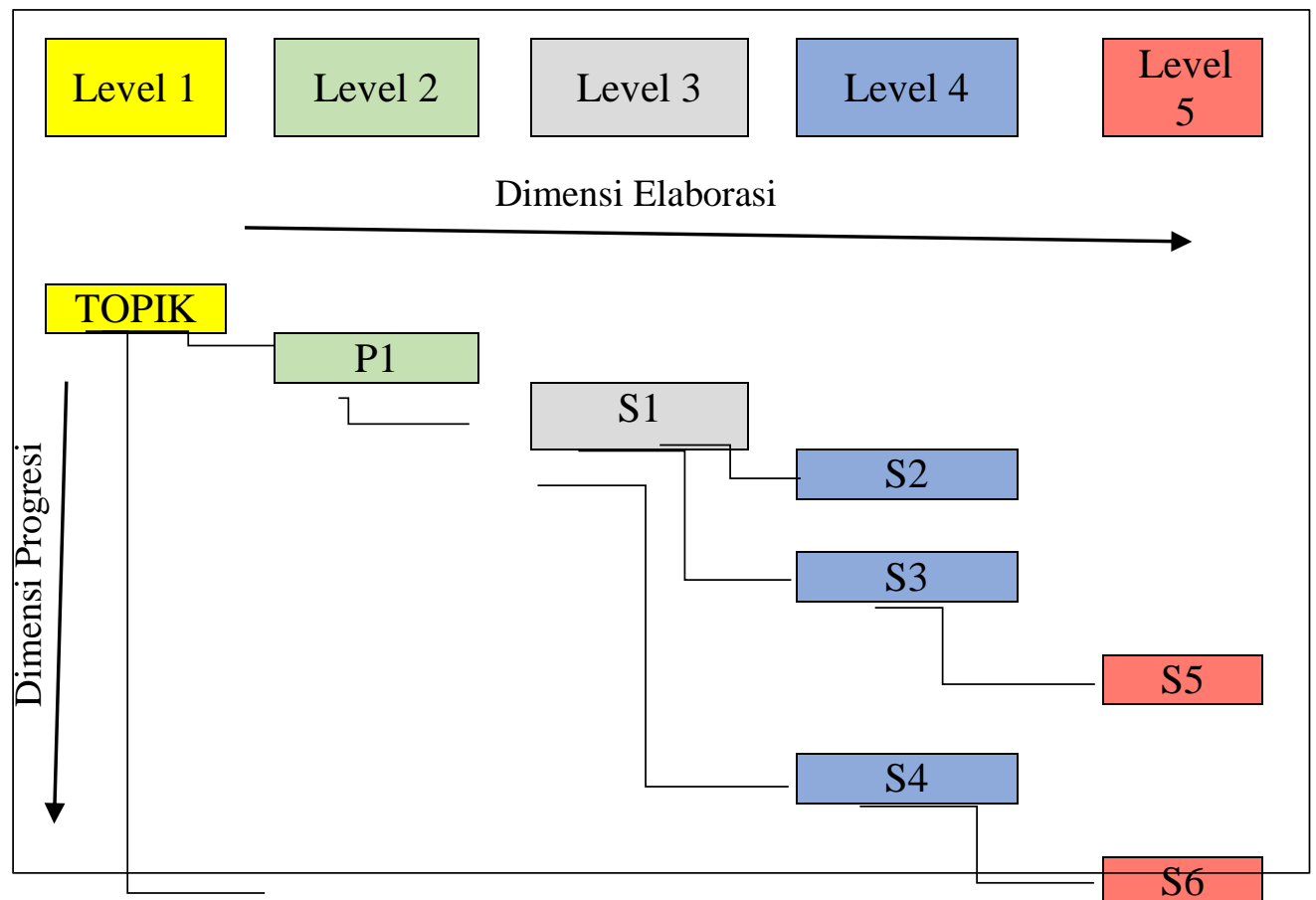

\section{P2}

Bagan 1 Struktur Makro Wacana (Vitrianti, 2012:21)

Keterangan: $\mathrm{P}=$ Proposisi makro, $\mathrm{S}=$ Proposisi mikro

Level 1,2,3,dst= Berdasarkan Kesetaraan Label Konsep

\section{HASIL PENELITIAN DAN PEMBAHASAN}

Label konsep yang terdapat pada buku A sebanyak 27 label konsep dengan jenis representasi antara lain 2 tipologi makroskopik dalam bentuk teks narasi, 26 tipologi submikroskopik dalam bentuk teks narasi, 8 tipologi submikroskopik dalam bentuk gambar, 5 tipologi simbolik dalam bentuk narasi, dan 9 tipologi simbolik dalam bentuk gambar. Label konsep yang terdapat pada buku B sebanyak 32 label konsep dengan jenis representasi antara lain lain 2 tipologi makroskopik dalam bentuk teks narasi, 3 tipologi makroskopik dalam bentuk teks gambar, 31 tipologi submikroskopik dalam bentuk teks narasi, 13 tipologi submikroskopik dalam bentuk gambar, 4 tipologi simbolik dalam bentuk narasi, dan 16 tipologi simbolik dalam bentuk gambar.

Kesesuaian label konsep buku teks A dan buku teks B terhadap silabus kimia kurikulum 2013 terdapat 31 label konsep yang sesuai dengan silabus kimia K-13 dari total 32 label konsep Struktur makro wacana buku A, dan B dibangun 
berdasarkan label konsep. Dengan Struktur makro buku A mencapai level 7 dimensi elaborasi, dan buku B mencapai level 7 dimensi elaborasi. Kriteria representasi kimia konsep struktur atom pada buku A terdapat 21 representasi, dan pada buku B terdapat 26 representasi.

\section{SIMPULAN}

Label konsep yang terdapat pada buku A sebanyak 27 label konsep. Label konsep yang terdapat pada buku B sebanyak 32 label konsep. Kesesuaian label konsep buku teks A dan buku teks B terhadap silabus kimia kurikulum 2013 terdapat 31 label konsep yang sesuai. Struktur makro wacana buku A mencapai level 7 dimensi elaborasi, dan buku B mencapai level 7 dimensi elaborasi. Kriteria representasi kimia konsep struktur atom pada buku A terdapat 21 representasi, dan pada buku B terdapat 26 representasi.

\section{DAFTAR PUSTAKA}

Arikunto, S., (2010). "Prosedur Penelitian Suatu Pendekatan Praktik", Jakarta: PT. Rineka Cipta.

Chang, R. 2010. Chemistry $10^{\text {th }} \mathrm{ed}$. New York: McGraw-Hill.

Departemen Pendidikan Nasional. 2005. Peraturan Pemerintah No.11 Tahun 2005 Tentang Buku Teks Pelajaran. Jakarta: BSNP.

Gilbert, J.K., \& Treagust, D.F. 2008. Multiple Representations in Chemical Education: Models and Modeling in Science Education. Dorgrecht: Springer. Pp. 251-283.

Gilbert, J.K., \& Treagust, D.F. 2009. Introduction: Macro, Submicro and Symbolic Representations and the Relationship Between Them: Key Models in Chemical Education, dalam Gilbert dan Treagust (Eds). Multiple Representations in Chemical Education: Model and Modeling in Science Education. Dorgrecht: Springer.1-8.

Gkitzia, V., Salta, K dan Tzougraki, C. 2011. "Development and Application of Suitable Criteria for the Evaluation of Chemical Representations in School Textbooks", Chemistry Education Research and Practice, 12: 5-14.

Herron, J Dudley. 1977. Problem Associated with Concept Analysis. JS E, 61(2),185-199.

Huddle, P. A., White, M. A \& Rogers, F. 2000. Using a Teaching Model to Correct Know Misconception in Electrochemistry. Journal of Chemical Education, Vol 77 (1): 104-110.

Johnstone, A. H. 1982. Macro-and Micro-Chemistry, School Science Review., 227, No. 64. P. 377-379. 
Kean, Elizabeth dan Middlecamp, Catherine. 1985. A Survival Manual for General Chemistry (Paduan Belajar Kimia Dasar). Penerjemah: A. Hadyana Pudjaatmaka. Jakarta: Gramedia.

Muslich, Mansur. 2010. Text Book Writing. Jakarta: Ar-Ruzz Media.

Nakhleh, M. 1992, Why Some Student Dont Learn Chemistry, Journal of Chemical Education.

Olayele. 2012. Enhancing Teachers" Knowledge for Using Multiple Representations in TeachingChemistry in Nigerian Senior Secondary Schools. Australia: Edith Cowan Universit.

Peraturan Menteri Pendidikan Nasionl. 2007. Peraturan Menteri Pendidikan Nasional Republik Indonesia No 41 Tahun 2007 tentang Standar Proses untuk Satuan Pendidkan Dasar dan Menengah. Jakarta: Depdiknas.

Sudarmo, U. (2013). Kimia Untuk SMA/MA Kelas X. Jakarta: Erlangga.

Sukardi. 2013. Metodologi Penelitian Pendidikan Kompetensi dan Praktiknya. Jakarta: Bumi Aksara.

Sunyono. 2015. Pembelajaran Model Simayang Tipe II untuk Meningkatkan Model Mental dan Penguasaan Konsep. FKIP: Universitas Lampung.

Suyatinah. 2001. Analisis Buku Teks Bahasa Indonesia Sekolah Dasar Kelas II. Yogyakarta: Laporan Penelitian FIP-UNY.

Tarigan, H, Guntur. 1986. Membaca Sebagai Suatu Ketrampilan Berbahasa. Bandung: Angkasa.

Tarigan, H, Guntur. 2009. Pengkajian Pragmatik. Bandung: Angkasa.

Watoni, Abdul Haris. 2016, Kimia 1 Untuk Kelas X SMA dan MA. Bandung: Yrama Widya.

Wulandari, S.H., Fatah, A.H. and Anggraeni, M.E. 2019. Analisis Materi Ajar Kimia SMA/MA Kelas XII Pada Konsep Sifat Koligatif Larutan. Jurnal Ilmiah Kanderang Tingang. 10, 2 (Dec. 2019), 300-320.

Zumdahl. (2007). Chemistry Sevent Edition. New York: Houghtn Mifflin Compani. 